\title{
Trends in the incidence of carcinoma in situ and cervical cancer in Ukraine
}

\author{
N. Tsip.1,2, Y. Mykhaylovich1, Z. Fedorenko1, O. Sumkina1, L. Kutsenko', M. Lyzogub3, M.A. Khalfalla \\ 1National Cancer Institute, Kyiv, Ukraine \\ 2Shupyk National Medical Academy of Postgraduate Education, Kyiv, Ukraine \\ ${ }_{3}$ National Bogomolets Medical University, Kyiv, Ukraine
}

\section{Background}

Despite visual localization, cervical cancer (CC) remains one of the most common malignant tumors in women. According to GLOBOCAN, in 2018 there were 569,847 new cases of CC in the world (the 4th most common cancer in women worldwide) and 61,072 new cases in Europe (the 8th most common cancer in women in Europe). Mortality statistics are also depressing: 31,165 deaths were registered in 2018 in the world (the 4th most common cause of cancer deaths in women) and 25,829 deaths in Europe (the 10th most common cause of cancer deaths in women in Europe).

According to GLOBOCAN, Ukraine ranks 11th in incidence and 6th in mortality from cervical cancer in Europe.

Screening in oncology is the only method that allows identifying the disease at the early and preclinical stages, reducing the duration of treatment, the cost of maintaining a hospital fund and the disability of patients. CC meets all requirements for population screening. The first step towards the development of an organizational and legal model for the introduction of a population screening for CC in Ukraine is the analysing of the incidence of cervical carcinoma in situ (CIS) and cervical cancer.

\section{Aim}

To study the trends in the incidence of CIS (code ICD-10 D06), compared with CC (ICD-10 C53) in Ukraine during the 2006-2016 period.

\section{Methods}

The methods of statistical analysis in descriptive oncoepidemiology were used to process the data. Based on the principles and methodology of medical informatics, the quality control of primary information was conducted in the database of the National Cancer Registry of Ukraine and the samples were formed. A cohort of patients with cervical cancer included 56579 cases; a cohort of patients with carcinoma in situ - 12387 cases.

Calculation of incidence rates was carried out per 100 thousand of the population, as well as standardized according to the world standard updated incidence rates of the population in the 2006-2016 period.

As the loss from CC in reproductive age affects the labor and reproductive potential of the country, the 2026 predicted rates of incidence in the age groups $0-29,30-39$ and $40-49$ were estimated.

To calculate the 2026 predicted rates, a 2-order polynomial regression with the calculation of the R2 to assess the credibility of the approximation was used.

Table 1. Calculation of CC incidence predicted rates

\begin{tabular}{|c|l|l|l|}
$\begin{array}{c}\text { Tumor } \\
\text { type }\end{array}$ & Age group & \multicolumn{1}{|c|}{ Polynomial regression } & \multicolumn{1}{c|}{$\begin{array}{c}\text { Coefficient of } \\
\text { determination }\end{array}$} \\
\hline \multirow{2}{*}{$\begin{array}{c}\text { Cervical } \\
\text { cancer }\end{array}$} & $0-29$ years & $\boldsymbol{y}=-0.0007 \boldsymbol{x}^{2}+0.0879 \boldsymbol{x}+0.3498 ;$ & $\mathbf{R}^{2}=0,88$ \\
\cline { 2 - 5 } & $30-39$ years & $\boldsymbol{y}=0,006 \boldsymbol{x}^{2}+0.2803 \boldsymbol{x}+10,261 ;$ & $\mathbf{R}^{2}=0,90$ \\
\cline { 2 - 5 } & $40-49$ years & $\boldsymbol{y}=0.0235 \boldsymbol{x}^{2}-0.5692 \boldsymbol{x}+30.986 ;$ & $\mathbf{R}^{2}=0,89$ \\
\hline
\end{tabular}

The data processing was carried out using the programs of the National Cancer Registry of Ukraine information system.

\section{Results}

While the incidence rate of CC (code ICD-10 C53) in Ukraine remains virtually unchanged over the past 10 years (about 20 cases per 100,000 female population), the incidence of CIS (code ICD-10 D06) tends to increase (from $3,5 \%$ in 2006 to $5,8 \%$ o000 in 2016).

The correlation between the incidence of CIS and CC in Ukraine in 2016 varied from 0.04 to 0.74 in different regions of the country and averaged 0.23 (Table 2) The ratio of the contingent index of the patients with CC and CIS, registered at the oncological hospitals of Ukraine ranged from 0.01 to 0.50 and averaged 0.18 (Table 2).

Table 2. Morbidity and prevalence of CIS and CC in Ukraine, 2016

\begin{tabular}{|c|c|c|c|c|c|c|c|c|c|}
\hline \multirow{3}{*}{ Country } & \multirow{2}{*}{\multicolumn{2}{|c|}{$\begin{array}{l}\text { Number of } \\
\text { cases, } \\
2016\end{array}$}} & \multirow{2}{*}{\multicolumn{3}{|c|}{$\begin{array}{c}\text { Morbidity, } \\
\text { standardized rates, } \\
2016 \text { p. }\end{array}$}} & \multicolumn{4}{|c|}{ Contingents } \\
\hline & & & & & & \multirow{2}{*}{$\begin{array}{c}\text { absolute } \\
\text { number, } \\
\text { D06 }\end{array}$} & \multicolumn{3}{|c|}{$\begin{array}{l}\text { rates per } 100 \text { thousand } \\
\text { female population }\end{array}$} \\
\hline & D06 & C53 & D06 & C53 & $\begin{array}{l}\text { D06/ } \\
\text { C53 }\end{array}$ & & D06 & C53 & $\begin{array}{l}\text { D06/ } \\
\text { C53 }\end{array}$ \\
\hline raine & 1122 & 4894 & 4.8 & 15.2 & 0.23 & 12387 & 64.0 & 269.5 & 0.18 \\
\hline
\end{tabular}

The problem of timely diagnosis and treatment of CIS becomes not only medico-biological, but also socio-economic, as the incidence rate of this pathology reaches peak values in young age groups [30-39 years] (Figure 1). Cervical cancer ranks third in the structure of female reproductive cancers in Ukraine.

The proportion of women of reproductive age among all primary patients with CC is $48.5 \%$.
Figure 1. Age-related morbidity rates of cervical cancer and cervical carcinoma in situ

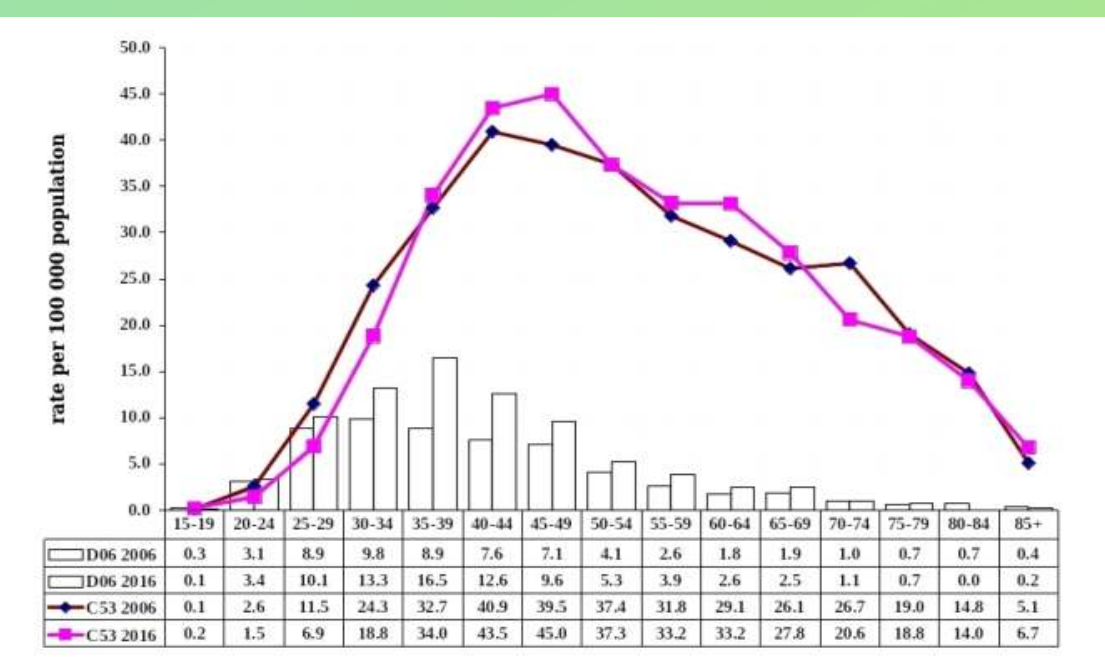

The largest increase in the incidence rates registered in the age groups - 0-29 and 30-39 years undoubtedly affects the labor and demographic potential of the population of Ukraine.

The study of the dynamics of CIS and CC incidence rates in the 2006-2016 period at reproductive age women showed that the in situ cancer rate increased to $40.0 \%$ (4.0\% annually), while CC was characterized by a decrease in the incidence rate by $8.0 \%$ (Figure 2 )

However, CC in women of reproductive age was characterized by a decrease in the incidence rate of $8.0 \%$. It draws attention to the fact that in 2006 for every 3 cases of cervical cancer 1 case of CIS was diagnosed in 2006, while in 2016 this ratio was 1.8.

Figure 2. Dynamics of cervical cancer and cervical carcinoma in situ morbidity in reproductive age women

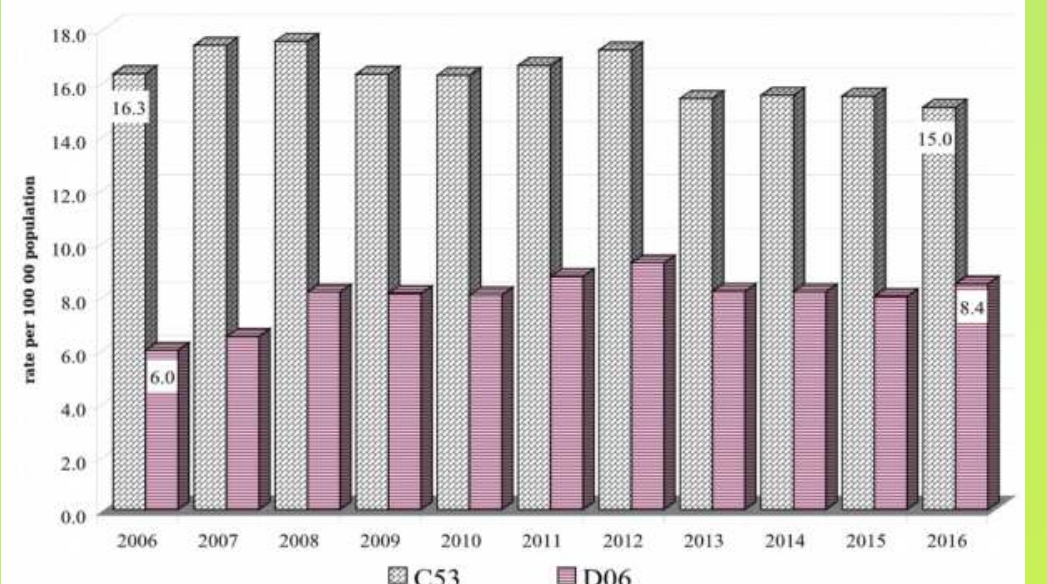

According to estimates, the predictive rate of CC incidence in the 0-29 year group has a steady upward trend, and although the index will not exceed 3,0\% increase over 20 years (2006-2026) will reach 23.4\%.

The incidence of CC in women 30-39 years in 2026 will be 39,3\% with an increase of 23.4\%; in the group of 40-49 years this indicator will increase to $61,3 \%{ }_{0000}$, an increase of $29,8 \%$ (Figure 3 ).

Figure 3. Predictive estimation of the $C \mathrm{C}$ incidence in reproductive age women

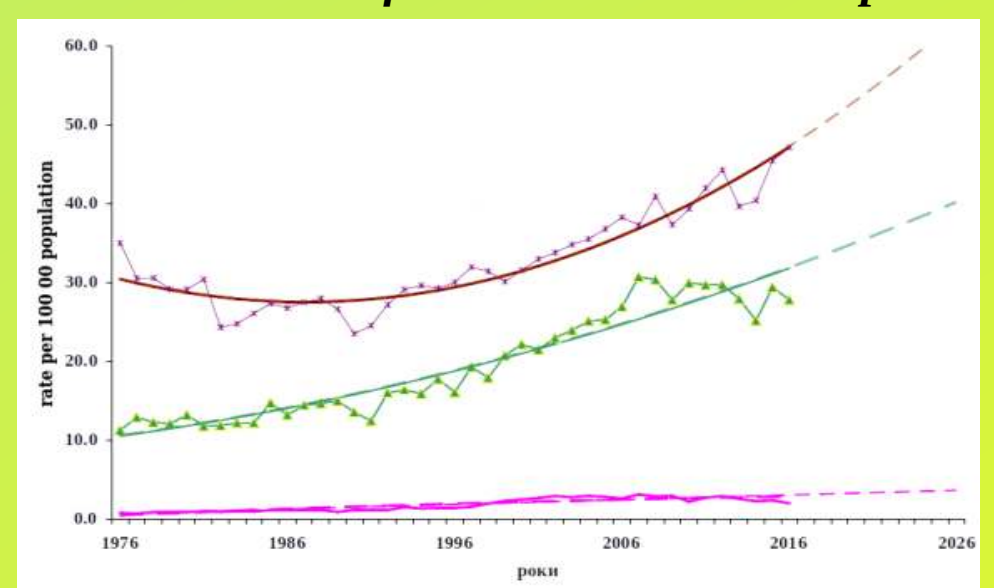

This oncoepidemiological situation in the cohort of reproductive age women underscores the urgency of the implementation of population-based CC screening, especially among women of younger age groups.

An increase in the incidence of CC in women of reproductive age and the "aging" of motherhood leads to the fact that at the time of detection of CC in the patient either the reproductive function is not realized, or the disease is diagnosed during pregnancy.

\section{Conclusion}

The problem of prompt diagnosis and treatment of cervical carcinoma in situ and cervical cancer acquires not only medical and biological but also socioeconomic value, since the incidence of this pathology reaches peak values in women of reproductive age, which directly affects the labor and demographic potential of the population in Ukraine.

By 2026, with the maintenance of existing preventive measures, an increase in the incidence of $\mathrm{CC}$ in reproductive age women is predicted.

The way to solve this problem is to strengthen the material and technical base and implement the State Program 'Cervical Cancer Screening'. 